\title{
A Study on Physical Model Test for Cheongpyeong Dam Discharge Recalculation
}

\author{
Joongu Kang, Sungjoong Kim, Hongkoo Yeo \\ Water Resource Research Department, Korea Institute of Construction Technology, Goyang, Korea \\ Email: jgkang04@kict.re.kr
}

Received 8 August 2014; revised 5 September 2014; accepted 15 September 2014

Copyright (C) 2014 by authors and Scientific Research Publishing Inc.

This work is licensed under the Creative Commons Attribution International License (CC BY). http://creativecommons.org/licenses/by/4.0/

(c) (i) Open Access

\section{Abstract}

Cheongpyeong Dam was built in 1943 for the purpose of power generation. Since its construction, discharge flow data based on a theoretical formula have been used to the present times and this leads to a problem of accurate discharge flow information not being available. In particular, Cheongpyeong Dam has been partially repaired and modified to maintain the dam structure over a long period of time and is not being properly reflected with changes at the downstream of the river caused by river improvement projects and sedimentation in reservoir. With a goal to improve Cheongpyeong Dam discharge flow calculation, this study aimed at verifying discharge capability and discharge flow by damper opening in relation to the previously suggested discharge flow through a hydraulic model test based on an accurate reproduction of the dam structure and surrounding topographies as in the present conditions. In this study, a hydraulic model test was conducted to examine the discharge flow of Cheongpyeong Dam. In addition, a comparative examination was carried out against the existing discharge flow proposed using theoretical equations. As a verification of the discharge flow of Cheongpyeong Dam, discharge flows in all sluices and a single sluice were examined. Then, the impact of sluice interference caused by the dam structure consisting with 24 sluices was investigated. As a result of the examination, it was found that the difference between discharge flow calculated using the existing theoretical equations and discharge flow derived from the hydraulic model test was insignificant. Based on the results of hydraulic model test, a formula to estimate stage-discharge flow at a sluice was derived and suggested.

\section{Keywords}

Cheongpyeong Dam, Hydraulic Model Test, Stage-Discharge Curve Recalculation 


\section{Introduction}

Completed in 1943, Cheongpyeong Dam is a hydroelectric dam controlled by Korea Hydro \& Nuclear Power. Approximately $71 \%$ of the basin area of Cheongpyeong Dam, which is located on Han River system, is Hongcheon River basin. Therefore, it has a geographical disadvantage that even a small amount of rain of approx. 20 $\mathrm{mm}$ can cause the water level to exceed the design flood level. Rapid changes in inflow caused by localized torrential downpour lead to a water level increase, which results in difficulty of stable dam operation. Therefore, for a stable dam operation, it is necessary to estimate and examine the discharge flow accurately. In addition, as problems associated with Cheongpyeong Dam, not only it is an old dam built over 70 years ago, but also accurate discharge flow of the dam is not available as discharge data based on theoretical equations have been used without verifications through hydraulic model test since construction. In particular, although the dam structure has been continuously maintained and changed over a long period of time, the related data have not been reflected. Changes in environment surrounding the dam structure have not been properly reflected, either. Therefore, for optimized Cheongpyeong Dam sluice operation, it is necessary to verify the existing calculation method based on theoretical equations. For this, verification through a hydraulic model test to accurately reproduce the dam structure and surrounding topography in their current states is required.

This study, with a goal to improve Cheongpyeong Dam discharge flow calculation, aimed at comparatively analyzing and examining discharge flow data of the past calculated using theoretical equations against discharge capability and discharge flow by damper opening produced through a hydraulic model test. In addition, it was intended to provide data for optimized sluice operation by calculating accurate discharge flow of Cheongpyeong Dam.

\section{Cheongpyeong Dam Status}

As shown in Figure 1, Cheongpyeong Dam is located in Bukhan River system in Korea and the basin area is $9921 \mathrm{~km}^{2}$. In terms of administrative district, the left bank of the dam borders Cheongpyeong-ri of Oeseo-myeon and Hoegok-ri of Seorak-myeon in Gapyeong-gun of Gyeonggi-do and the right bank borders Cheongpyeong-ri, Oeseo-myeon, Gapyeong-gun of Gyeonggi-do. In the basin area of Cheongpyeong Dam, Pyeonghwaeui Dam (Peace Dam), Hwacheon Dam, Chuncheon Dam and Euiam Dam are located at the upstream of Bukhan River as well as Soyanggang Dam of Soyang River that flows to the left bank of Bukhan River. As major rivers in the basin area in between Euiam Dam and Cheongpyeong Dam, there are Bukhan River, a national river where Cheongpyeong Dam is located, and Hongcheon River that flows to the left bank of Bukhan River. As regional rivers, seven and 17 rivers flow respectively to the left and the right banks of Bukhan River and 33 rivers flow into Hongcheon River and join Bukhan River. In the basin area between Euiam Dam and Cheongpyeong Dam, there are one national river and 58 regional rivers [1].

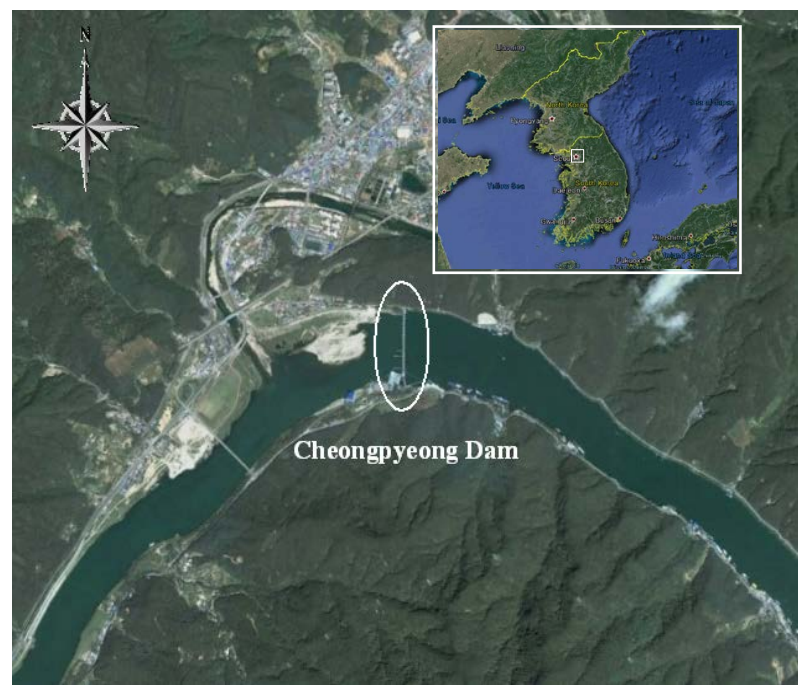

Figure 1. Cheongpyeong Dam location map. 
As shown in Figure 2, Cheongpyeong Dam is a concrete gravity dam measuring $31.0 \mathrm{~m}$ in height, $407.0 \mathrm{~m}$ in length and 250,000 $\mathrm{m}^{3}$ in capacity. Elevations at the top of the dam and of spillway are EL. $53.00 \mathrm{~m}$ and EL. $41.00 \mathrm{~m}$ respectively. As a discharge facility during flood, 24 roller gates measuring $12.0 \mathrm{~m} \times 10.0 \mathrm{~m}$ each are installed. Design flood stage and design flood discharge are EL. $52.00 \mathrm{~m}$ and 20,736 m³ respectively and normal pool level is EL. 51.00 m. Water level limit during flood is EL. $50.00 \mathrm{~m}$ [2]. Specifications of Cheongpyeon Dam and reservoir are listed in Table 1.

\section{Hydraulic Model Establishment}

\subsection{Hydraulic Model Scale}

Hydraulic model scale is determined through a composite review of reproducibility, ability of flow supply to test lab, test model manufacturing space and measuring convenience. In general, river models have smaller water depth in comparison to the channel length and width. Therefore, considering the scale of model, a distorted model is used for successful flow reproduction. However, in case a structure installed within a river is the key target of interest, a normal model must be used in order to reproduce three-dimensional (X, Y and Z directions) flow behavior, such as the impact of turbulence around the structure. When a model using distorted scale is applied, it involves distortion in flow analysis around a structure. As a result, accurate flow analysis is disabled. To use a normal model, it is necessary to secure the maximum water depth considering precision of water level measurements for the model. Accordingly, it is possible for the size of model to become excessively large.

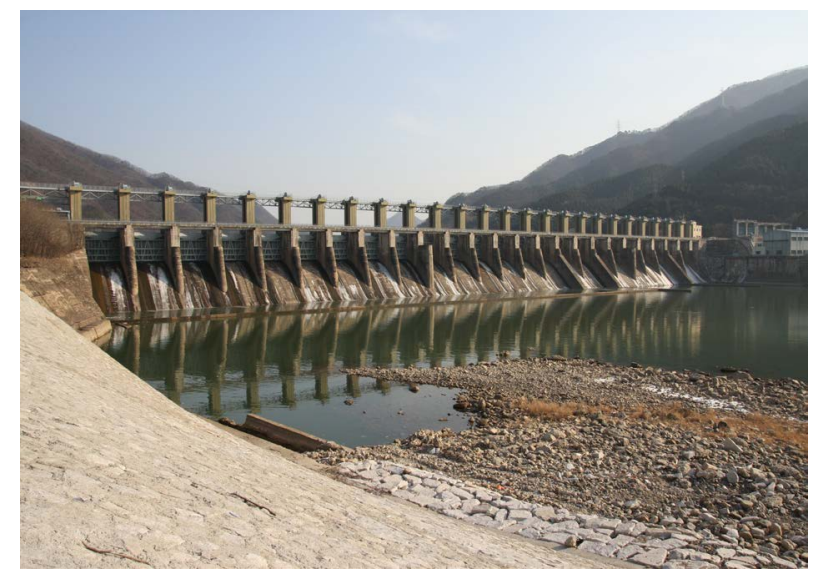

Figure 2. View of Cheongpyeong Dam.

Table 1. Cheongpyeong Dam specifications [3].

\begin{tabular}{|c|c|c|c|c|}
\hline Large category & Classification & Specifications & Classification & Specifications \\
\hline \multirow{5}{*}{ Dam structure } & Type & Concrete gravity dam & Annual average inflow ( $\left.\mathrm{m}^{3} / \mathrm{s}\right)$ & 222.8 \\
\hline & Size (m) & $31(\mathrm{H}) \times 407(\mathrm{~L})$ & Water volume at sluice (EA) & 24 \\
\hline & Capacity $\left(\times 1000 \mathrm{~m}^{3}\right)$ & 250 & Sluice size (m) & $10(\mathrm{H}) \times 12(\mathrm{~L})$ \\
\hline & Annual average precipitation (mm) & 1379 & Sluice type & Roller gate \\
\hline & Elevation at the top of spillway (EL. m) & 41.0 & & \\
\hline \multirow{5}{*}{ Reservoir } & Basin area $\left(\mathrm{km}^{2}\right)$ & 9921 & Low water level (EL. m) & 46.0 \\
\hline & Maximum water surface area $\left(\mathrm{km}^{2}\right)$ & 17.6 & Total storage (million $\mathrm{m}^{3}$ ) & 185.5 \\
\hline & Design flood stage (EL. m) & 52.0 & Max. discharge Flow $\left(\mathrm{m}^{3} / \mathrm{s}\right)$ & - \\
\hline & Normal pool level (EL. m) & 51.0 & Design flood discharge $\left(\mathrm{m}^{3} / \mathrm{s}\right)$ & $20,000[4]$ \\
\hline & Limit stage (EL. m) & 50.0 & Flood control capacity (million $\mathrm{m}^{3}$ ) & 19 \\
\hline
\end{tabular}


Therefore, it is important to decide an appropriate size. Considering all of the conditions above, Cheongpyeong Dam hydraulic model was created as a normal model with a horizontal scale of 1/50 and a vertical scale of 1/50. Hydraulic conversion ratios of the hydraulic test model are listed in Table 2.

\subsection{Physical Model Test}

For a hydraulic model production, a topographical model production is carried out first. To produce a topographical model, the space for model installation is cleaned and then surveying is carried out with total station to set sidelines as reference lines for the model. Then, based on control points of the model, external walls are built leaving a space of a set length considering height of the model using blocks and the walls are applied with mortar. A considerable amount of earth pressure is applied to the external walls. Therefore, to prevent the model from being destroyed by falling, inside of the blocks are filled and a secondary protection is applied to the walls. When outer walls are built, a topographical plane is installed. For this, a cross-sectional diagram of the riverbed obtained through actual surveying of the river is printed out in the scale of test model. Then, plywood is cut out in the shape of the diagram including embankments, waterways and waterfront areas, and thus a topographical plane is created by sideline. The topographical plane is placed at an accurate position using total station by each sideline (Figure 3). For filling in between topographical planes, filling material (sand, etc.) is laid out as in Figure 4 and is shaped using cement mortar as in Figure 5 according to the riverbed cross-section recreated on plywood. The topographical planes are connected as precisely as possible by referring to the ground plane and topographic map so as to recreate a topographical shape that is the same as the actual topography. When the topography of reservoir and channel is configured, the complete dam structure is oriented. Then, by accurately reproducing topography in joints using survey data, a hydraulic model is completed (Figure 6).

Table 2. Scale for hydraulic model test and hydraulic volume conversion ratio.

\begin{tabular}{ccc}
\hline Hydraulic conversion ratio & Conversion formula & Model scale \\
\hline Horizontal length scale & $X_{r}$ & 50 \\
Vertical length scale & $Y_{r}$ & 50 \\
Area ratio & $X_{r} Y_{r}$ & 2500 \\
Velocity ratio & $Y_{r}^{1 / 2}$ & 7.07 \\
Flow ratio & $X_{r} Y_{r}^{3 / 2}$ & 17677.67 \\
Slope ratio & $Y_{r} X_{r}$ & 1 \\
Roughness coefficient ratio & $X_{r}^{-1 / 2} Y_{r}^{2 / 3}$ & 1.92 \\
\hline
\end{tabular}

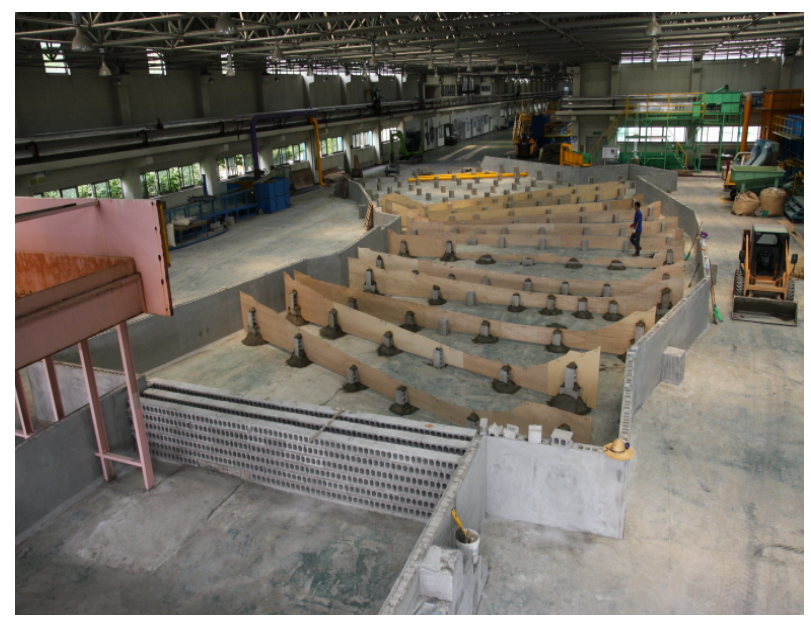

Figure 3. Creating Cheongpyeong Dam topography. 


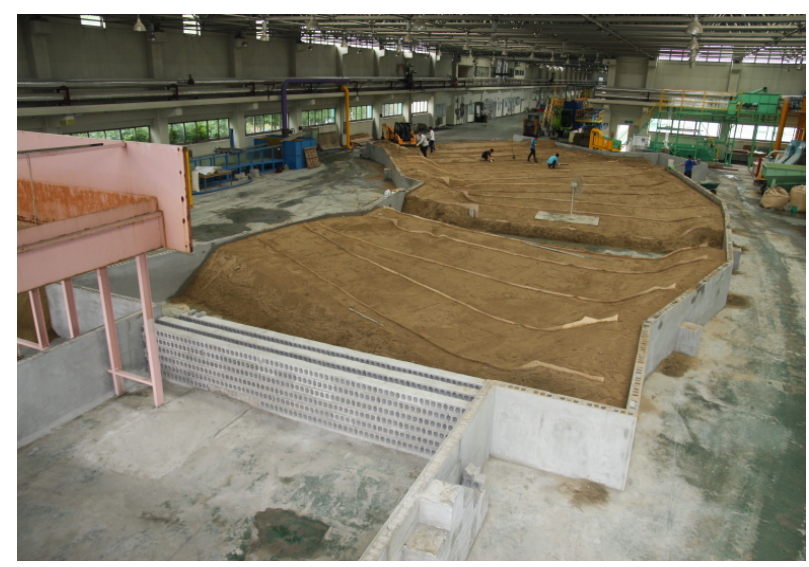

Figure 4. Sand spreading.

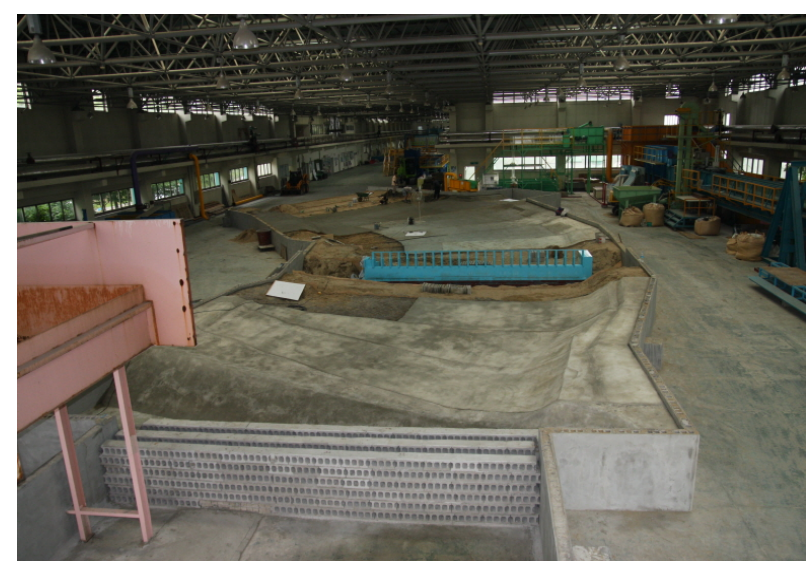

Figure 5. Shaping up \& downstream channel.

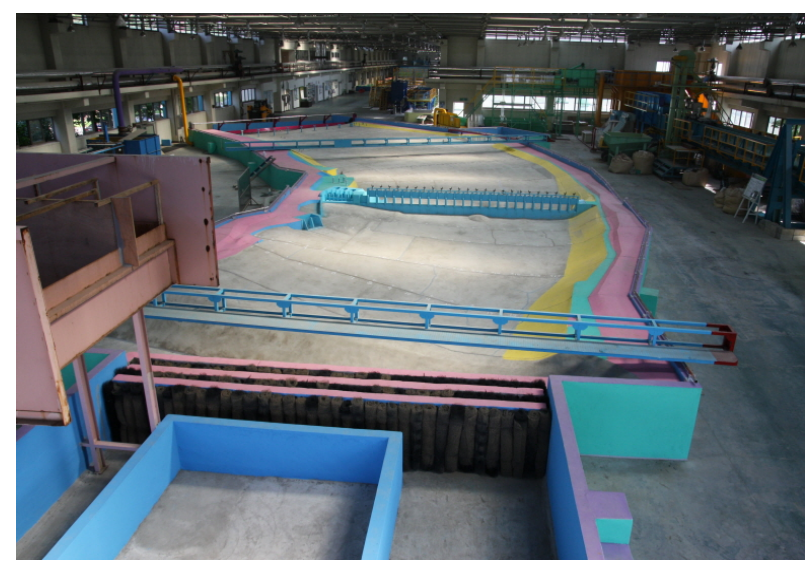

Figure 6. Cheongpyeong Dam hydraulic model.

\subsection{Water Supply Device}

In a hydraulic model test, stable supply of the flow must be ensured without any fluctuations during the test. To supply accurate and consistent flow required by the hydraulic model test, it is most important to maintain stable water level in the higher tank and a sufficient amount of water in the lower tank. Considering the scale of model, Cheongpyeong Dam hydraulic model test requires large flow. Therefore, it was ensured to supply flow by up to $1.3 \mathrm{~m}^{3} / \mathrm{s}$ using a total of three pumps. For water supply tanks in Cheongpyeong Dam hydraulic model test, 
high-precision full-width weirs were used as shown in Figure 7. According to literature review, the method of using flow supply tanks has the highest reliability and is most frequently used in hydraulic model tests [5]. For full-width weir formula applied to this test, IDEYA DEJIMA equation of Equation (1) was used.

$$
\begin{gathered}
Q=C B h^{3 / 2} \\
C=1.785+0.00295 / h+0.237 h / D-0.428 \sqrt{B h / B D}+0.034 \sqrt{B / D}
\end{gathered}
$$

where $Q$ is discharge $\left(\mathrm{m}^{3} / \mathrm{s}\right), B$ is the width of supply tank $(\mathrm{m}), h$ is water depth from the end of weir $(\mathrm{m}), C$ is flow coefficient and $D$ is the height from the bottom to the end of weir $(\mathrm{m})$. The equation of full-width weir is used limitedly according to the weir specifications. In this study, rating curve was calculated as in Figure 8 and was used in the model test.

\section{Cheongpyeong Dam Discharge Capability Examination and Estimation Equation Development}

\subsection{Examination of Existing Discharge Flow Estimation Equation}

Cheongpyeong Dam uses stage-discharge flow curve calculated using the large orifice flow equation proposed in the past without a hydraulic model test at the time of design. Flow through the sluice gate is defined as in Figure 9. Discharge flow calculation is carried out using Equation (2) below.

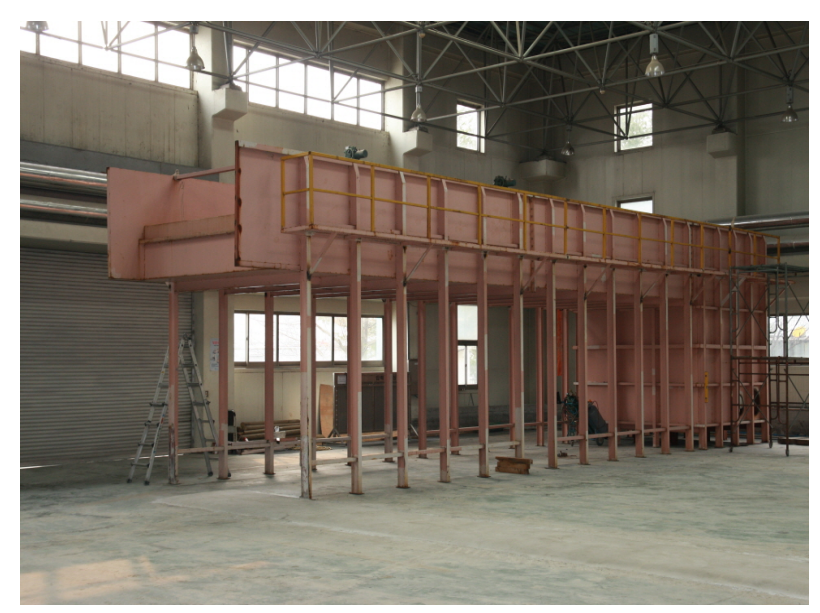

Figure 7. Full-width weir for Cheongpyeong Dam test.

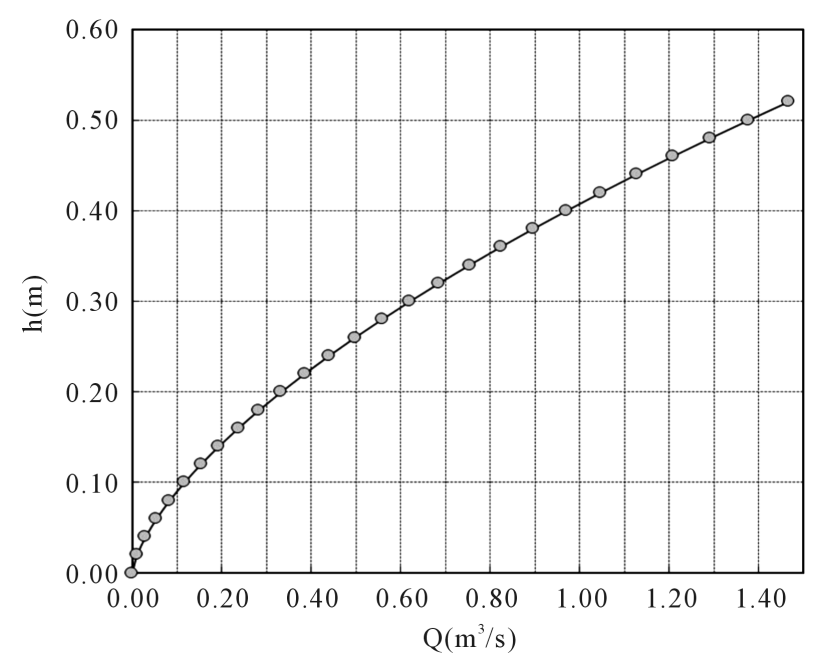

Figure 8. $2.0 \mathrm{~m}$ full-width weir rating curve. 


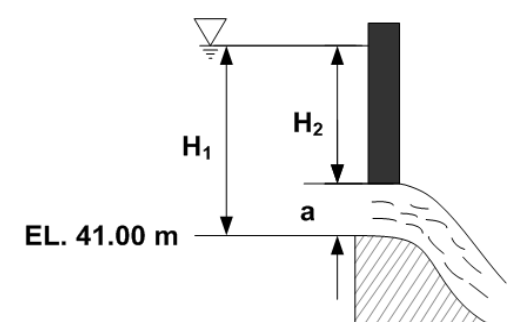

Figure 9. Flow through sluice gate (Korea Hydro \& Nuclear Power, 2004).

$$
Q=\frac{2}{3} K \sqrt{2 g} B\left(H_{1}^{3 / 2}-H_{2}^{3 / 2}\right)
$$

where, $Q$ is discharge $\left(\mathrm{m}^{3} / \mathrm{s}\right), K$ is discharge coefficient $(0.67-0.74$ according to $a), g$ is gravitational acceleration $\left(9.8 \mathrm{~m}^{3} / \mathrm{s}\right), B$ is the width of sluice gate $(12 \mathrm{~m}), a$ is the height of damper opening $(\mathrm{m}), H_{1}$ and $H_{2}$ are total head $(\mathrm{m})$ in relation to weir crest and the bottom of sluice including approach velocity head.

The problems associated with Cheongpyeong Dam discharge flow calculation at the moment are that the flow coefficient $(K)$ is being estimated in an empirical method and that flow according to sluice opening is calculated by applying the same flow to all 24 sluice gates based on flow data obtained from a single sluice gate. To solve these problems, it is necessary to check accurate values through discharge flow verification test at each sluice gate and to make improvement through this process. Therefore, for discharge flow examination, this study investigated the impact of sluice gate interference, compared discharge flows estimated using theoretical equations, compared difference in discharge flow at each sluice gate and suggested a stage-discharge curve equation using test results.

\subsection{Comparison of Discharge Capability with Existing Data}

Verification for discharge flow examination was carried out under the conditions of all sluices fully opened and of one sluice gate fully opened. Discharge flow data were analyzed using the existing data and hydraulic model test results. As for the existing data, discharge flow data suggested in Hydraulic Operation Source Book [6] were used (Min. water level suggested in the data is EL. $48.00 \mathrm{~m}$ - EL. $52.50 \mathrm{~m}$. Flow is suggested by water level). When all sluices gates were completely opened, difference in discharge flow between hydraulic model test and the previous operation data was within $2.0 \%$. In addition, when a single sluice gate was fully opened, the difference was found to be within 4.0\% (Figure 10, Figure 11). Considering errors of hydraulic model test, it is considered that the discharge flow data from hydraulic model test match the data suggested in the previous operation data.

\subsection{Development of Estimation Equation through Test of Discharge Capability in One Sluice Gate}

The test by opening of a single sluice gate in Cheongpyeong Dam was conducted in order to examine the difference in discharge flows at one out of a total of 24 sluice gates in the dam structure. The test was divided into a test on full opening of a single sluice gate and a test on discharge capability according to the height of sluice gate opening. Prior to the test on discharge capability in relation to a single sluice gate, a test to examine discharge flow in seven sluice gates was carried out in order to understand the difference in discharge flows from each sluice gate. As for the test by opening of each sluice gate, discharge flow from seven sluice gates (No. 1, 6, 12, 13, 18, 20 and 24) equally distributed from the left and the right banks was examined. Stage-discharge flow curve at complete opening of each sluice gate is as shown in Figure 12. As a result of the test, it was found that there was no difference in discharge flow from each sluice gate. This is because, when a single sluice gate is opened, impact of topography at the upstream of dam and velocity head is insignificant. Therefore, it is considered that there would be no problems in sluice gate selection in case of sluice gate control by reason of differences in discharge capabilities.

The examination of discharge capability according to the height of a single sluice gate opening was carried out on sluice gate No. 12 at the interval of $1.0 \mathrm{~m}$ within the opening height range of $1.0 \mathrm{~m}-6.0 \mathrm{~m}$. The graph of 


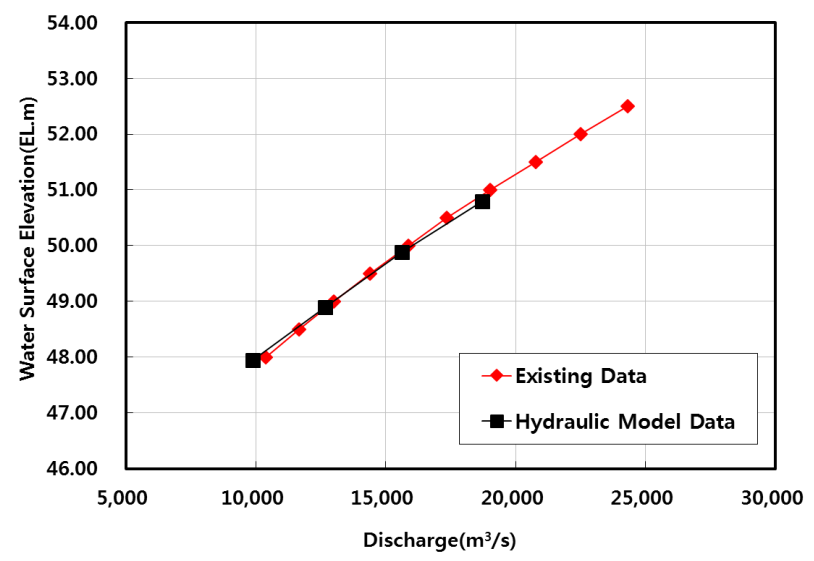

Figure 10. Stage-discharge flow curve for discharge flow verification (all sluice gates open).

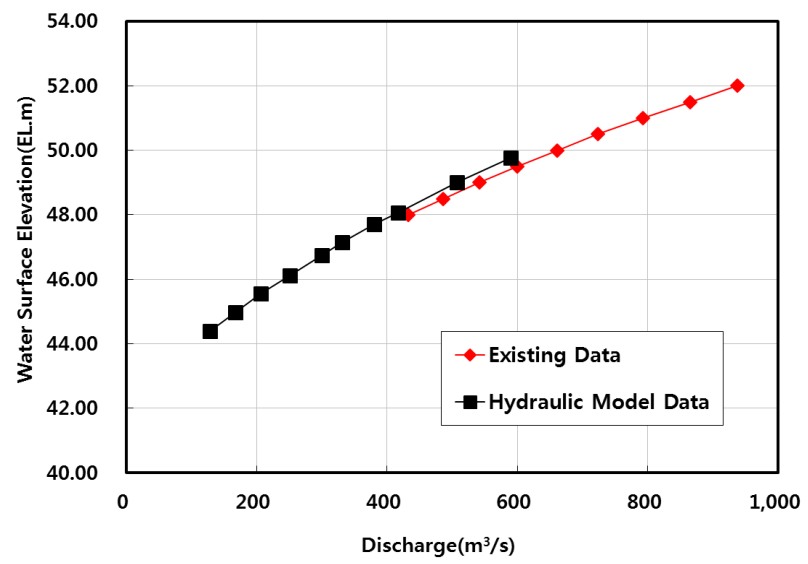

Figure 11. Stage-discharge flow curve for discharge flow verification (one sluice gate open).

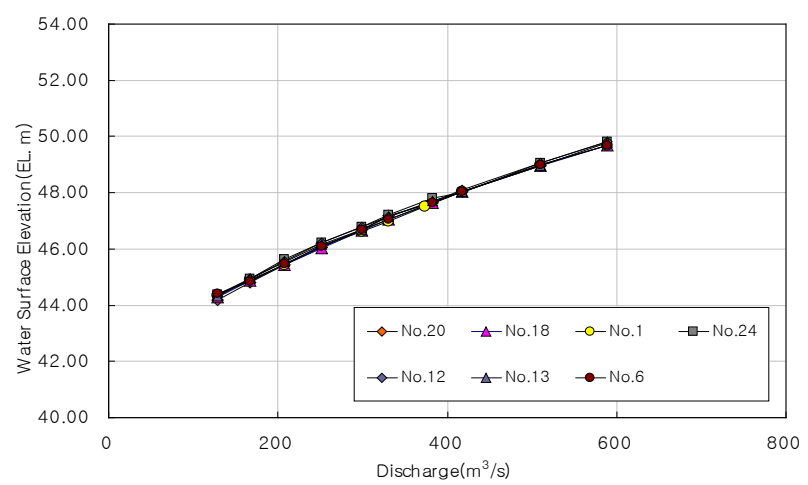

Figure 12. Stage-discharge curve (one gate full opened).

stage-discharge flow relationship measured through the hydraulic model test is shown in Figure 13. Based on the results, stage-discharge flow curve equation according to a single sluice gate opening height was developed using a regression equation the least square techniques. The stage-discharge curve equation is suggested in Table 3.

\subsection{Sluice Gate Interference Examination}

Cheongpyeong Dam is a long-span dam consisting with a total of 24 sluice gates. In general, when flood occurs, 


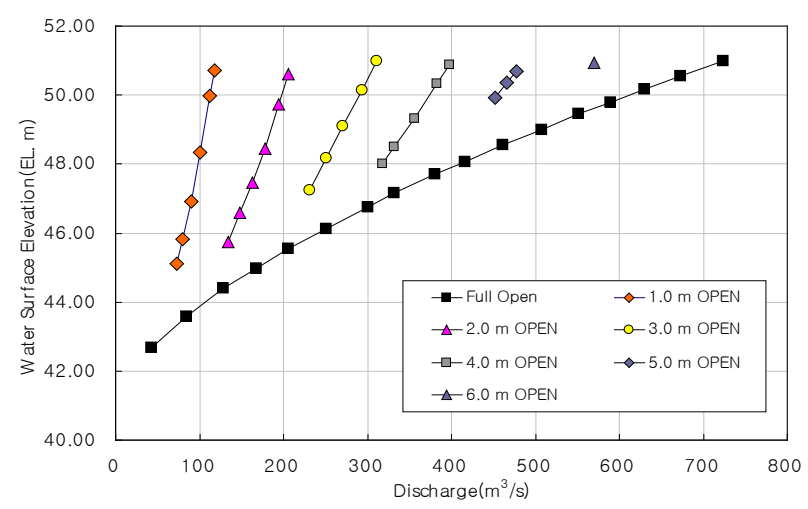

Figure 13. Stage-discharge curve (opening height).

Table 3. Stage-discharge equations according to one sluice gate opening height.

\begin{tabular}{cccc}
\hline Opening height (m) & Stage-discharge equations & $\mathrm{R}^{2}$ & Remarks \\
\hline 1 & $Q=-0.3279 H^{2}+39.3 H-1032.4$ & 0.99 & - \\
2 & $Q=-0.592 H^{2}+71.87 H-1914.8$ & 0.99 & - \\
3 & $Q=0.1431 H^{2}+7.4646 H-440.78$ & 0.99 & - \\
4 & $Q=-0.1727 H^{2}+44.972 H-1442.7$ & 0.99 & - \\
5 & $Q=-1.2479 H^{2}+158.51 H-4350.8$ & 0.99 & Prediction formula \\
6 & $Q=-3.6324 H^{2}+402.08 H-10486$ & 0.99 & \\
FULL OPEN & $Q=4.4292 H^{2}-332.46 H+6161.4$ & 0.99 & - \\
\hline
\end{tabular}

where, $Q$ is discharge $\left(\mathrm{m}^{3} / \mathrm{s}\right), H$ is water surface level (EL. $\left.\mathrm{m}\right)$.

the number of operating sluice gates increases and sluice gate operation is carried out simultaneously. However, when neighboring sluice gates are opened at the same time, it interferes with flow around the structure, and thus a difference may occur in discharge flow from each sluice gate. Therefore, to estimate an accurate discharge flow, hydraulic characteristics of sluice gate interference must be examined first. The test on the impact of sluice gate interference is aimed at examining the impact on flow caused by sluice gate operation. In this study, water level and flow regime were examined at each sluice gate.

As in Table 4, the test on sluice interference impact was planned under the condition of five different separation distances. The largest sluice gate separation distance was set as five times and, as for sluice gate opening conditions, two conditions, such as opening by $4.0 \mathrm{~m}$ and complete opening, were set considering pressure flow occurrence and free surface occurrence conditions. The test was conducted on sluice gates No. 12 - 17 located in the middle in order to eliminate the impact of drift caused by topography on the left and the right banks. Figure 14, Figure 15 show the scenes of test under case 1 and case 3 conditions respectively.

Examination items for the impact of interference according to sluice separation distance are water level and flow regime. Data on water level observation are shown in Table 4 and data on flow regime observation are schematized in Figure 16 and Figure 17. Figure 16 and Figure 17 are represented experiment on gate operation cases. To examine the impact of interference according to sluice gate distance, water level and flow regime were observed while changing sluice gate separation distance from one to five times. As for water level difference examination targeting average water level observed near sluice gates, water level differences were calculated from measurements under each condition of text No. 1 listed in Table 5. According to water level measurements under conditions 1 - 5 in Table 5, water level difference at full sluice gate opening was measured within the range of $2.4-4.1 \mathrm{~cm}$ when the water level measurements were converted to actual model values and the maximum water level difference was found to be $4.1 \mathrm{~cm}$ when the sluice separation distance was five times. In case of sluice gate opening by $4.0 \mathrm{~m}$, the water level difference was $0.7-6.4 \mathrm{~cm}$ and the maximum water level difference was $6.4 \mathrm{~cm}$ when the separation distance was four times. Considering conditions in the test site (wind, 


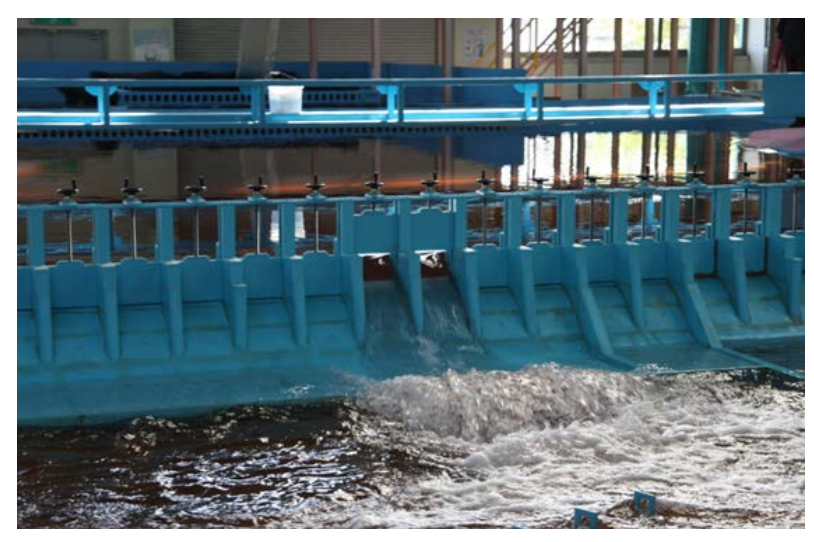

Figure 14. Impact of sluice gate interference (case 1).

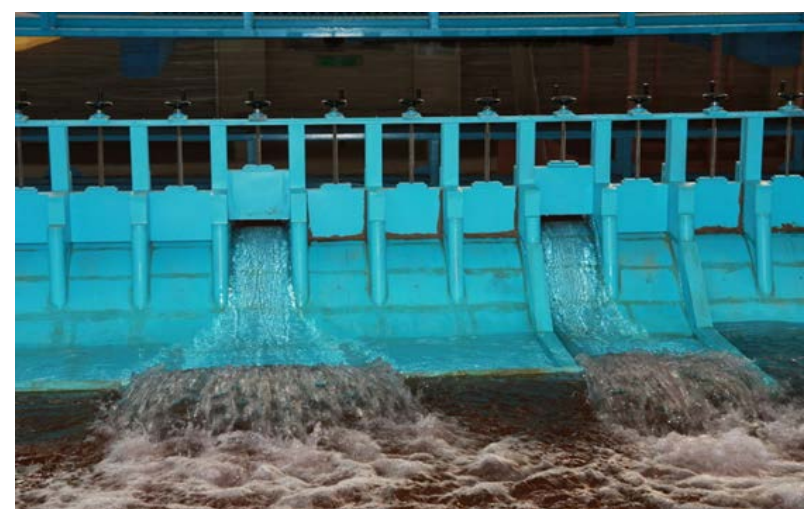

Figure 15. Impact of sluice gate interference (case 4).

Table 4. Sluice gate interference impact test conditions.

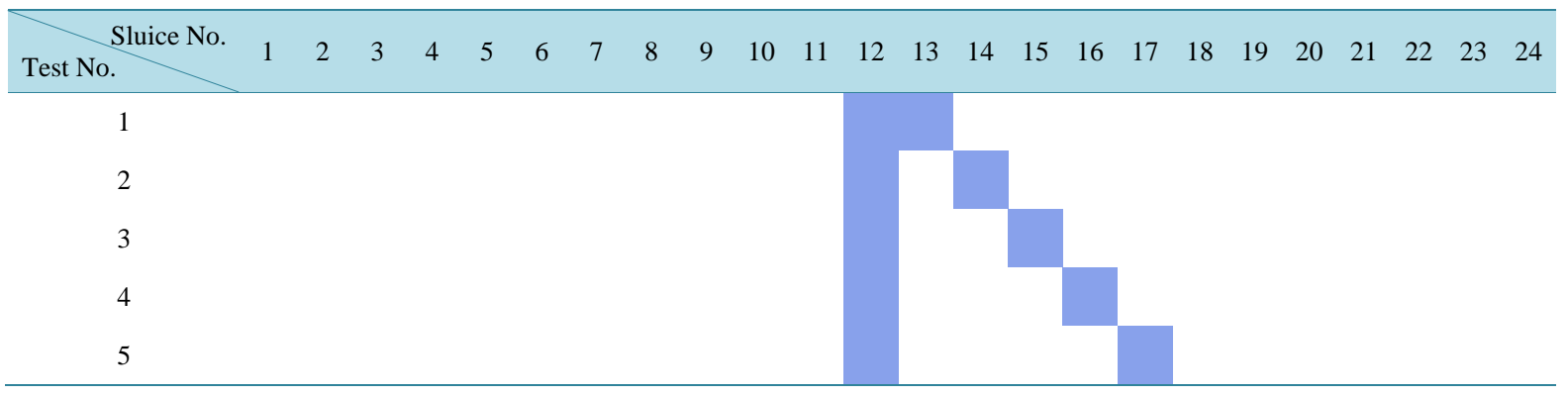

※Sluice gates numbered from right bank.

Table 5. Water level measurements.

\begin{tabular}{ccccc}
\hline Test No. & $\begin{array}{c}\text { Full Open } \\
\text { (EL. m) }\end{array}$ & $\begin{array}{c}\text { Water Level } \\
\text { Difference (m) }\end{array}$ & $\begin{array}{c}\text { Open by } 4 \mathrm{~m} \\
\text { (EL. m) }\end{array}$ & $\begin{array}{c}\text { Water Level } \\
\text { Difference (m) }\end{array}$ \\
\hline 1 & 50.096 & 0.000 & 50.074 & 0.000 \\
2 & 50.060 & -0.036 & 50.089 & 0.015 \\
3 & 50.071 & -0.025 & 50.061 & -0.013 \\
4 & 50.073 & -0.024 & 50.010 & -0.064 \\
Openarks & -0.007 \\
\hline
\end{tabular}

Note: water level difference based on condition No. 1. 


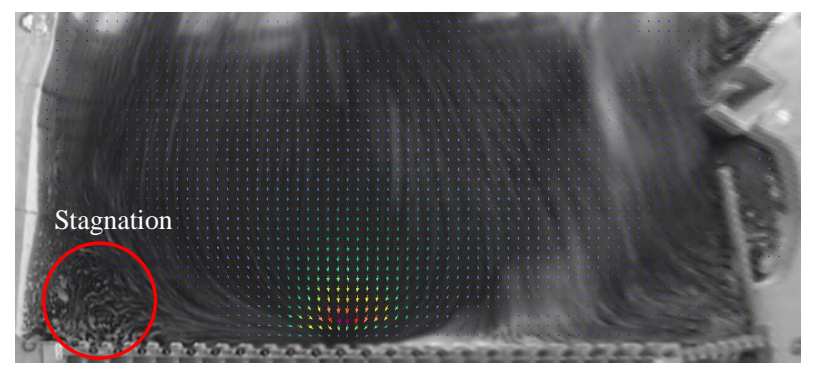

Figure 16. Impact of sluice gate interference (case 1).

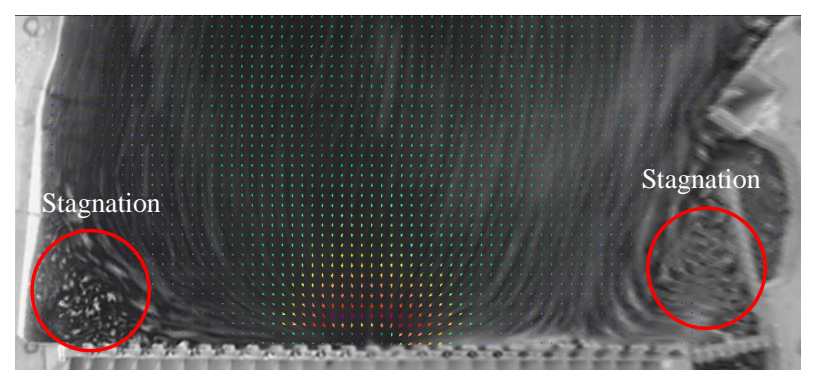

Figure 17. Impact of sluice gate interference (case 3).

etc.), such differences are considered insignificant. Therefore, it is considered that there is no interference impact caused by sluice separation distance. As a result of flow regime examination using LSPIV (Large Scale Particle Image Velocimetry), it was found that a completely stagnant flow occurs near the right bank where sluice gate No. 1 is located and an insignificant vortex is formed as a result of the topographical features of intake No. 4 near the left bank where the power plant intakes are located. When sluice gate interval is increased by more than three times, flow at the entrance displays a pattern of inflow to each sluice gate.

\section{Conclusions}

Cheongpyeong Dam was built more than half a century ago in Korea. Without any proper hydraulic model test data, it has been used to the present times with the discharge flow calculated based on theoretical equations of the past. With a goal to verify and recalculate Cheongpyeong Dam discharge flow in order to secure reliability of the data, this study reexamined discharge capability of the dam through a hydraulic model test. Results of the hydraulic model test are as follows.

1) A hydraulic model for Cheongpyeong Dam was created in the scale of $1 / 50$ to accurately reflect the current state of the dam by reflecting the changed reservoir and topography at the downstream of channel through examination of past design data and topographical surveying. Then, through a test, the discharge flow was reexamined.

2) As for the method of Cheongpyeong Dam discharge flow calculation, problems have been identified that the method of discharge flow calculation based on theoretical equations continues to be used in the present times and that a method to apply uniformed flow discharge to all 24 sluice gates is being maintained.

3) As a result of comparing discharge flow data obtained through the hydraulic model test and discharge flow data calculated using theoretical equations, it was found that there are no differences in discharge flow.

4) By examining impact on flow around sluice gate exerted by flow interference during sluice gate-linked operation, it was confirmed that no interference was caused by sluice gate distance. In addition, as a result of examining discharge flows targeting seven equally distributed sluice gates, it was found that there was no difference in discharge flows.

5) Through a hydraulic model test on Cheongpyeong Dam, stage-discharge flow curves were prepared according to damper opening heights at a single sluice gate and the related empirical equations were suggested. Therefore, using the empirical formulas for discharge flow calculation suggested through the hydraulic model test, it will be possible to calculate discharge flow more accurately than before. 


\section{Acknowledgements}

This research was supported by the Internal Research Project (2014) of the Korea Institute of Construction Technology.

\section{References}

[1] Korea Hydro \& Nuclear Power (2007) Hydroelectric Dam Flood Prevention Plan Establishment Report.

[2] Korea Hydro \& Nuclear Power (2007) Cheongpyeong Hydraulic Power Facility Extension (Unit 4 Installation) Design Service Numerical Analysis and Hydraulic Model Test Report.

[3] Han River Hydraulic Power Generation Office (2003) Cheongpyeong Storage Estimation Service Report.

[4] Ministry of Construction and Transportation (2002) Bukhan River Improvement Basic Plan (Supplemented) Report.

[5] Itata and Dejima (1951) Discharge Coefficient of Suppressed Weir Based on Rehboek's Formula. Transaction of the Japan Society of Mechanical Engineers, 17. http://www.docin.com/p-113544715.html

[6] Korea Hydro \& Nuclear Power (2004) Hydraulic Power Facility Operation Sourcebook. 
Scientific Research Publishing (SCIRP) is one of the largest Open Access journal publishers. It is currently publishing more than 200 open access, online, peer-reviewed journals covering a wide range of academic disciplines. SCIRP serves the worldwide academic communities and contributes to the progress and application of science with its publication.

Other selected journals from SCIRP are listed as below. Submit your manuscript to us via either submit@scirp.org or Online Submission Portal.
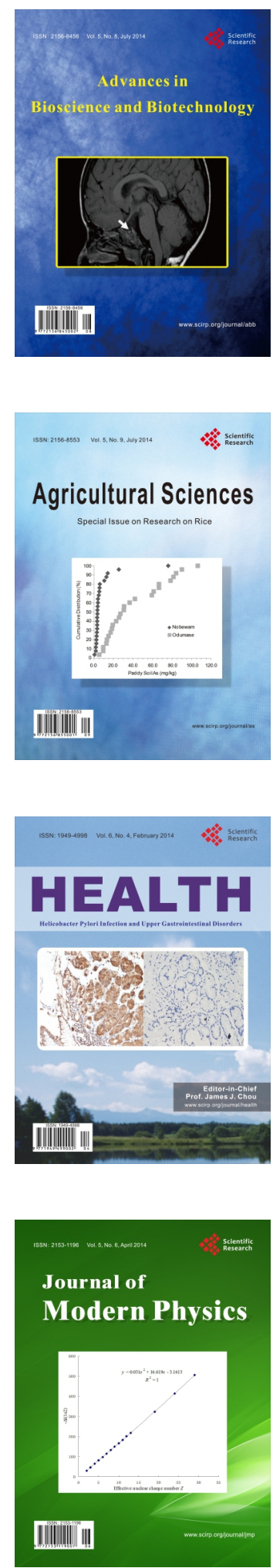
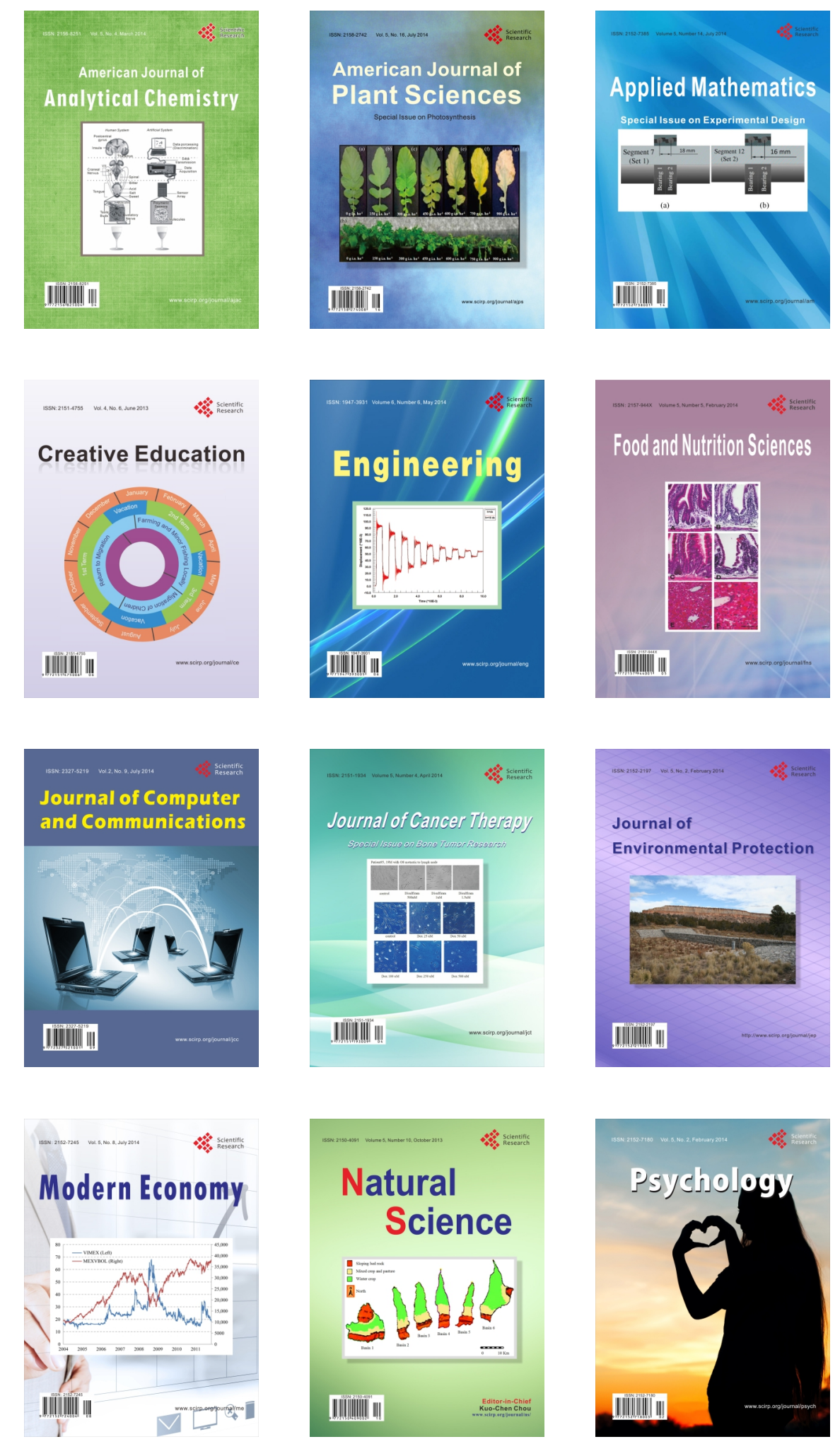